\title{
Length-Dependence of Electron Transfer Coupling Matrix in Polyene Wires: Ab Initio Molecular Orbital Theory Study
}

\author{
GOVIND MALLICK, ${ }^{1}$ SHASHI P. KARNA, ${ }^{1}$ HAIYING HE, ${ }^{2}$ \\ RAVINDRA PANDEY ${ }^{2}$ \\ ${ }^{1}$ US Army Research Laboratory, Weapons and Materials Research Directorate, Attn: AMSRD-ARL- \\ WM-BD, B-4600, Aberdeen Proving Ground, MD 21005-5069 \\ ${ }^{2}$ Department of Physics, Michigan Technological University, Houghton, MI 49931
}

Received 1 July 2008; accepted 8 September 2008

Published online 20 January 2009 in Wiley InterScience (www.interscience.wiley.com).

DOI 10.1002/qua.21927

\begin{abstract}
The electron transfer (ET) properties of $\pi$-electron conjugated quasione-dimensional molecular wires, consisting of polyene, $[>\mathrm{C}=\mathrm{C}<]_{n}(n=1-11)$, including $\beta$-carotene, is investigated using ab initio molecular orbital theory within Koopmans theorem (KT) approach. The ET coupling matrix element, $V_{\mathrm{DA}}$, for 1,3-transbutadiene molecule calculated with the KT approach shows excellent agreement with the corresponding results obtained with two-state model. The calculated values of $V_{\mathrm{DA}}$ for the polyene oligomers exhibit exponential decrease in magnitude with increasing length of the wire. However, the decay curve exhibits three different regimes. The magnitude of the decay constant, $\beta$, decreases with the increase in length of the wire. A highly delocalized $\pi$-electron cloud in the polyene chain appears to facilitate retention of the electronic coupling at large separations between the donor and acceptor centers. (C) 2009 Wiley Periodicals, Inc. Int J Quantum Chem 109: 1302-1310, 2009*
\end{abstract}

Key words: electron transfer; molecular orbitals; $\beta$-carotene

Correspondence to: G. Mallick; e-mail: gmallick@arl.army.mil or S. P. Karna; e-mail: skarna@arl.army.mil

Contract grant sponsor: Director's Research Initiative (DRI).

Contract grant number: ARL-FY07-WMR-10.

Contract grant sponsor: Defense Advance Research Project Agency.

Contract grant number: ARL-DAAD17-03-C-0115.

(c) 2009 Wiley Periodicals, Inc. *This article is a US Government work and, as such, is in the public domain in the United States of America. 


\section{Introduction}

B ecause of its importance in a wide variety of chemical, biological, and photophysical phenomena, intermolecular electron transfer (ET) has been a subject of numerous theoretical [1-10] and experimental $[3,6,11,12]$ studies. Recent interest in molecular scale electronics [13-19] has further renewed interest in intramolecular ET. Studies performed to date suggest that ET in molecules is intimately related to their electronic and geometrical structures. Of particular interest is the length dependence [1, 17-20] of ET, as it determines the potential application of molecular systems in nanoscale electronics.

The molecular wires that have been considered for applications in molecular electronics can be divided into two categories, namely $\sigma$-bonded $n$-alkane chain $\left[\mathrm{CH}_{3}-\left(\mathrm{CH}_{2}\right)_{n}-\mathrm{CH}_{3}\right]$-based insulating wires $[13,14]$ and $\pi$-electron conjugated polyene $\left[(>\mathrm{CH}=\mathrm{CH}<)_{n}\right]$-based semiconducting wires $[15$, $16]$. $\beta$-Carotene, a member of polyene hydrocarbons, is a prototypical example of the second category. It is a naturally occurring organic molecule with nanoscale dimension (molecular length $\sim 3$ $\mathrm{nm}$ ) and highly conjugated $\pi$-electrons, which offer its excellent photophysical and nonlinear optical (NLO) properties. Because of its quasi-one-dimensional geometry and highly conjugated $\pi$-electrons delocalized over $\sim 3 \mathrm{~nm}$ in space, $\beta$-carotene also offers itself as a potential candidate for application in molecular electronics devices and has attracted attention in its electron transport property $[18,19]$. Ramachandran et al. [18] have reported contactmode atomic force microscopic measurements and theoretical calculations of the current-voltage (I-V) characteristics on thiol functionalized $\beta$-carotene molecules tethered on Au surface. These authors, not unexpectedly, reported that conductance of $\beta$-carotene to be much higher by a factor of seven than that of an alkane chain and also considerably higher than aromatic $\pi$-conjugated systems of comparable length. Very recently, He et al. [19] have derived the decay constant, $\beta$, of polyenes from a similar study on four carotenoid polyenes with the number of double bonds, $n=5,7,9$, and 11 in molecular backbone. They report a value of $\beta=$ $0.22 \pm 0.04 \AA^{-1}$ derived from the I-V measurements, in excellent agreement with the earlier theoretical value reported by Ramchandran et al [18].

Despite recent interest in electronics application of organic molecules, there remains a lack of de- tailed understanding of ET in quasi-one-dimensional polyenes. Here, we present the results of our systematic study of the length dependence of ET in $\pi$-conjugated quasi-one-dimensional molecular wires consisting of $\beta$-carotene as the largest member. We use ab initio molecular orbital (MO) theory approach to calculate the equilibrium structure and ET coupling matrix element, $V_{\mathrm{DA}}$, of $\beta$-carotene and its smaller oligomers. The calculated results show an exponential decay of $V_{\mathrm{DA}}$. However, the decay in $V_{\mathrm{DA}}$ exhibits three distinct regimes in the molecular wire, and the value of the decay constant decreases with increasing molecular length.

\section{Theory and Calculations}

The electron transfer rate constant $\left(K_{\mathrm{et}}\right)$ of weakly coupled electron donor (D) and acceptor (A) centers in a nonadiabatic limit is related to the electron transfer coupling strength, $V_{\mathrm{DA}}$, as [7, 21, 22]

$$
K_{\mathrm{et}}=\frac{2 \pi}{\hbar}\left|V_{\mathrm{DA}}\right|^{2} \mathrm{FCWD},
$$

where FCWD represents a Franck-Condonweighted density of states representing the nuclear modes of the system. The $V_{\mathrm{DA}}$, which plays a major role in the electron transfer process, represents the strength of the interaction between the two active reaction sites.

The distance dependence of the electron transfer rate is primarily determined by the $V_{\mathrm{DA}}$ as FCWD in Eq. (1) is weakly dependent on the site separation in a molecule $[3,11]$. Hence, we can write

$$
\left|V_{\mathrm{DA}}\right|^{2}=K_{\mathrm{o}} e^{-\beta R_{\mathrm{DA}}},
$$

where $K_{\mathrm{o}}$ is a prefactor, $R_{\mathrm{DA}}$ is the separation between the $\mathrm{D}$ and $\mathrm{A}$ centers, and $\beta$ is the decay constant, a characteristic of the organic molecular system

The coupling matrix, $V_{\mathrm{DA}}$, in a two-state model $[21,22]$ can be calculated as,

$$
V_{\mathrm{DA}}=\left\langle\Psi_{D}|H| \Psi_{A}\right\rangle \text {, }
$$

where, $H$ is the total Hamiltonian connecting the $\mathrm{D}$ and A states, represented by the many-electron wavefunctions, $\Psi_{\mathrm{D}}$ and $\Psi_{\mathrm{A}}$, respectively. Several different methods have been used in the literature to evaluate $V_{\mathrm{DA}}$ as discussed in detail by Newton 
and Curtiss et al. [7, 23, 24]. Because electron transfer is a one-electron process, Eq. (1) can be cast in terms of charge-localized, fully relaxed self-consistent wavefunctions, $\psi_{\mathrm{D}}$ and $\psi_{\mathrm{A}}$, respectively [4, 7, 23], whereby, we can write

$$
V_{\mathrm{DA} 1}=\left(H_{\mathrm{DA}}-S_{\mathrm{DA}} H_{\mathrm{DD}}\right) /\left(1-S_{\mathrm{DA}}^{2}\right),
$$

where,

$$
\begin{gathered}
H_{\mathrm{DA}}=\left\langle\psi_{\mathrm{D}}|H| \psi_{\mathrm{A}}>\right. \\
H_{\mathrm{DD}}=\left\langle\psi_{\mathrm{D}}|H| \psi_{\mathrm{D}}>\right. \\
S_{\mathrm{DA}}=<\psi_{\mathrm{D}} \mid \psi_{\mathrm{A}}>\neq 0 .
\end{gathered}
$$

For symmetric molecular geometries, as studied here, $\psi_{\mathrm{A}}$ and $\psi_{\mathrm{D}}$ represent symmetry-broken solutions of the Hamiltonian and are mirror image pair $\left(H_{\mathrm{DD}}=H_{\mathrm{AA}}\right)$ of each other. In Eqs. (4)-(7), $H_{\mathrm{DA}}$ represents the interaction strength between $\mathrm{D}$ and A states; $H_{\mathrm{DD}}=H_{\mathrm{AA}}$ is the degenerate expectation value of the Hamiltonian with respect to $\psi_{\mathrm{D}}$ and $\psi_{\mathrm{A}}$, and $S_{\mathrm{DA}}$ is the overlap matrix between the $\mathrm{D}$ and $\mathrm{A}$ state wavefunctions.

Liang and Newton $[4,5]$ have shown that $V_{\text {DA }}$ can also be calculated using symmetry delocalized self-consistent field (SCF) solutions, $\psi^{ \pm}$, within the mean-field approach, where $\psi^{+}$and $\psi^{-}$are the in-phase and out-of-phase combinations of $\psi_{\mathrm{D}}$ ad $\psi_{\mathrm{A}}$, given by;

$$
\psi^{ \pm} \sim\left(\psi_{\mathrm{D}} \pm \psi_{\mathrm{A}}\right) /\left(1 \pm S_{\mathrm{DA}}\right)^{1 / 2} .
$$

$V_{\mathrm{DA}}$ can then be calculated as one half of the energy splitting between the $\psi^{+}$and $\psi^{-}$states as,

$$
V_{\mathrm{DA}}=1 / 2\left(E^{+}-E^{-}\right) .
$$

Equation (9) can be cast into one-electron orbital energies using Koopmans theorem (KT) [25], whereby, one can write,

$$
V_{\mathrm{DA}}=1 / 2\left(\varepsilon^{+}-\varepsilon^{-}\right) .
$$

Various schemes have been proposed in the literature $[4,5,23,24]$ for a proper choice of the one-electron orbital energies in Eq. (10). The coupling element, $V_{\mathrm{DA}}$, can be calculated either for the cation or anion from the respective ionization potential (IP) and electron affinity (EA) energy levels within the KT approximation. The detailed theoret- ical analysis of various approaches can be found elsewhere $[4,5,23,24]$. Here, we have used the highest occupied (HO) and next-highest occupied $(\mathrm{NHO}))$ molecular orbitals of the neutral triplet $\left(M_{\mathrm{S}}\right.$ $=3$ ) diradical to calculate $V_{\mathrm{DA}}$ as [24],

$$
V_{\mathrm{DA}}=1 / 2\left(\varepsilon_{\mathrm{HOMO}}-\varepsilon_{\mathrm{HOMO}-1}\right) \text {, }
$$

where $\varepsilon_{\mathrm{HOMO}}$ and $\varepsilon_{\mathrm{HOMO}-1}$ are energies of the $\mathrm{HOMO}$ and the NHOMO, respectively, in the triplet state of the neutral molecule.

Both, Eqs. (4) and (11) have been used extensively $[3-7,9,20,23,24,26]$ to calculate $V_{\mathrm{DA}}$. Calculations of $V_{\mathrm{DA}}$ using Eq. (4) offers a self-consistent approach to calculate localized states but is computationally expensive. Eq. (11), on the other hand, offers a computationally less demanding and simple approach to calculate $V_{\mathrm{DA}}$. The simplicity and relatively less computational demands associated with the KT approach have made it an attractive choice for investigating ET properties of complex organic and biological systems $[3,4-6,9,20,24-$ 26]. Previous studies have shown $[7,23-26]$ that the accuracy of the $V_{\mathrm{DA}}$ calculated by $\mathrm{KT}$ approach is comparable to those obtained from more rigorous techniques, such as the Marcus-Hush (MH) twostate model [21, 22]. In order to further assess the accuracy of $V_{\mathrm{DA}}$ for linear $\pi$-electron chain molecules obtained with the use of the KT approach, we calculated the coupling matrix element for 1,3trans-butadiene using Eq. (4) with the MH two-state model as well as with the use of the KT approach, Eq. (11). The results, as discussed in next section, from the two methods are comparable to each other, lending confidence in the use of the KT approach for calculating $V_{\mathrm{DA}}$ for the polyene oligomers in this study.

To obtain equilibrium structure of the smaller polyene oligomers, the initial structural configurations with alternate single and double bonds were taken from the parent $\beta$-carotene molecule. Figure 1 displays the molecular structure of $\beta$-carotene and its smaller oligomers, $\left(R_{\mathrm{C}=\mathrm{C}}\right)_{n}$, where $n=1,3,5,7$, 9 , and 11 representing the number of $\pi$-bonds in the molecule, were considered. The polyene oligomer chains were terminated by methyl group at the end of each molecule as shown in Figure 2. A symmetry-constrained optimization was performed in the framework of ab initio unrestricted Hartree-Fock (UHF) method utilizing an extended basis set consisting of a double zeta augmented by one $\mathrm{p}$ and one d polarization functions (DZP) as implemented in the Gaussian package [27]. 


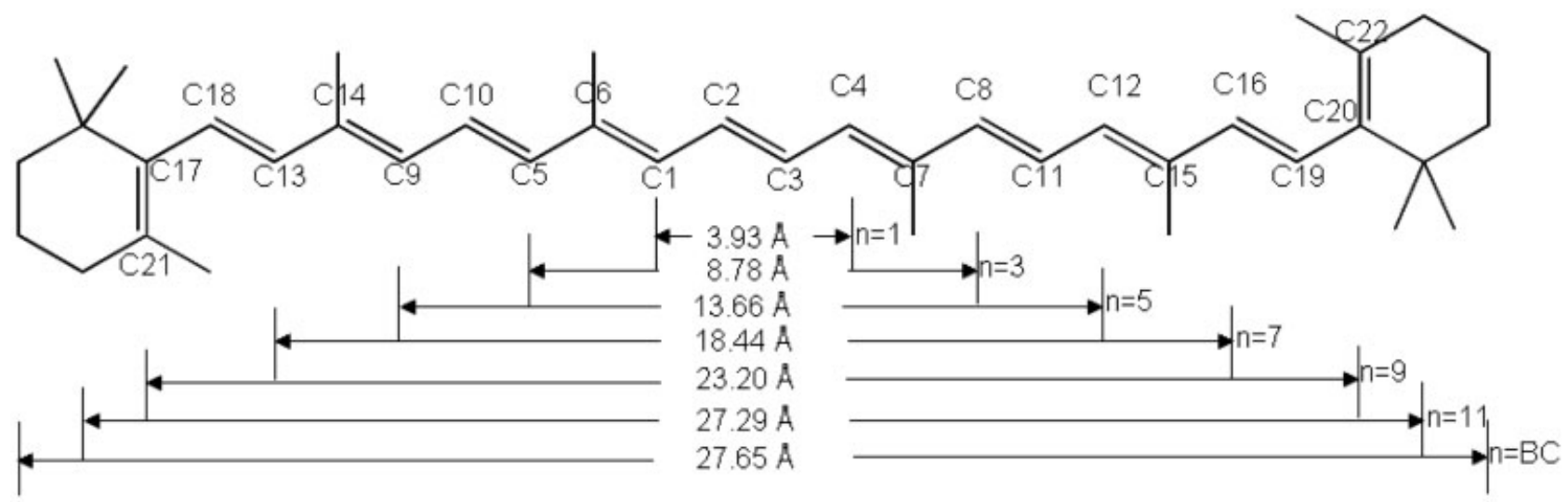

FIGURE 1. The equilibrium geometries of $\beta$-carotene and its derivatives including $\pi$-conjugated polymeric chains $[>C=C<]_{n}$, where $n$ is number of $\pi$-bonds ranging from 1 to 11 .

\section{Results and Discussion}

\section{THE GEOMETRY}

The optimized geometrical parameters of the polyene oligomers $(n=1-11)$ are summarized in Table I. In the equilibrium configuration of $\beta$-carotene, the calculated bond lengths associated with single and double bonds are 1.51 and $1.33 \AA$, respectively. Calculations [28] based on density functional theory (DFT) together with $6-31 \mathrm{G}(\mathrm{d}, \mathrm{p})$ basis set have been reported for the equilibrium structure

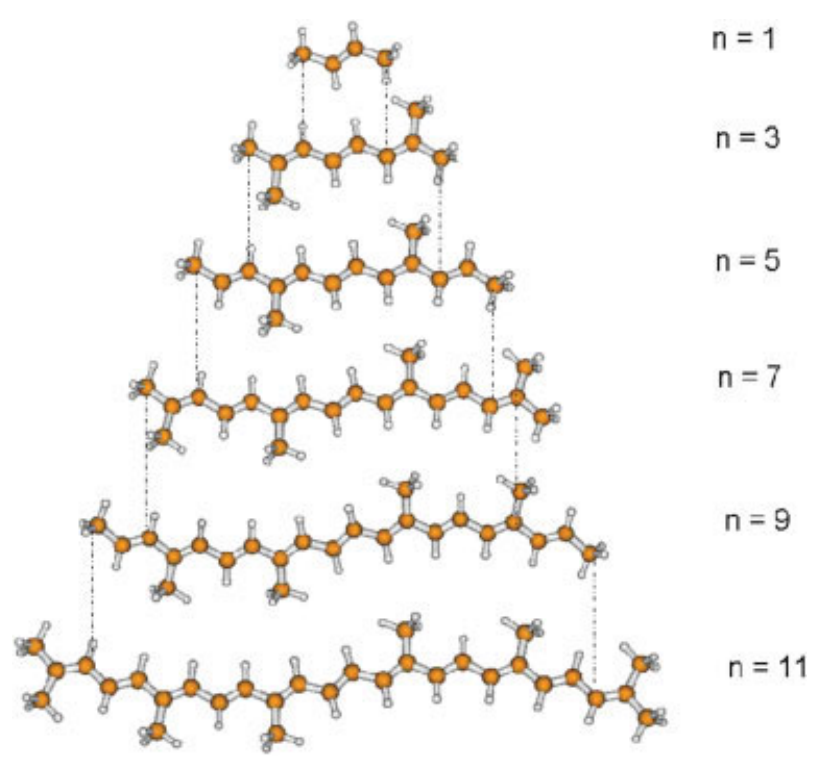

FIGURE 2. The ball and stick model of $\beta$-carotene oligomers. It also shows terminal methyl groups. of $\beta$-carotene radical cation. Our calculated values for the $R_{\mathrm{C}-\mathrm{C}}$ and $R_{\mathrm{C}=\mathrm{C}}$ are in good agreement with the corresponding DFT bond lengths of 1.45 and $1.37 \AA$, respectively. Similarly our calculated bond angles for $\beta$-carotene are in good agreement with the corresponding DFT values of $\beta$-carotene radical cation. The calculated bond lengths also compare well with the corresponding experimental data of 1.48-1.54 and 1.31-1.38 $\AA$ associated with single and double bonds, respectively, obtained from Xray diffraction measurements [29].

It is instructive to examine the change in bond lengths as a function of the chain length of the polyene oligomers. We notice that in going from $n=1$ to $n=3$, the central $R_{\mathrm{C}=\mathrm{C}}$ increases from $\sim 1.325$ to $\sim 1.336 \AA$, getting closer to the outer $R_{\mathrm{C}=\mathrm{C}}$ bonds, whereas the single bond lengths $\left(R_{\mathrm{C}-\mathrm{C}}\right)$ decrease from $\sim 1.501$ to $\sim 1.468 \AA$. Beyond $n=5$, the changes in the bond lengths are much smaller and the chain shows a nearly constant bond length alternation (b. 1 . a.) with double bond $\left(R_{\mathrm{C}=\mathrm{C}}\right)$ lengths to be $\sim 1.338-$ $1.339 \AA$ (see Fig. 3 ) and single bond $\left(R_{\mathrm{C}}-\mathrm{C}\right)$ lengths to be $\sim 1.468-1.462 \AA$. This suggests that in an idealized polyene with extended b.l.a., the $V_{\mathrm{DA}}$ will be essentially unchanged with the length of the wire.

\section{ELECTRON TRANSFER}

\section{Comparison of MH Two-State Model and K'T Approach.}

We performed calculations on the $V_{\mathrm{DA}}$ of 1,3trans-butadiene molecule using the charged localized SCF wavefunctions for the D and A states as well as with the use of the KT approach. The charge 
TABLE I

A summary of optimized geometrical parameters (bond lengths in $\AA$ ) of the polyene oligomers $(n=1-\beta$ carotene).

\begin{tabular}{|c|c|c|c|c|c|c|c|}
\hline & \multicolumn{7}{|c|}{ Bond lengths $(\AA)$} \\
\hline & $\beta$-Carotene & $n=11$ & $n=9$ & $n=7$ & $n=5$ & $n=3$ & $n=1$ \\
\hline \multicolumn{8}{|l|}{ Double bonds } \\
\hline $\mathrm{C} 2=\mathrm{C} 3$ & 1.339 & 1.339 & 1.339 & 1.339 & 1.338 & 1.336 & 1.325 \\
\hline $\mathrm{C} 1=\mathrm{C} 6 ; \mathrm{C} 4=\mathrm{C} 7$ & 1.343 & 1.343 & 1.343 & 1.343 & 1.341 & 1.335 & \\
\hline $\mathrm{C} 5=\mathrm{C} 10 ; \mathrm{C} 8=\mathrm{C} 11$ & 1.338 & 1.338 & 1.337 & 1.336 & 1.33 & & \\
\hline $\mathrm{C} 9=\mathrm{C} 14 ; \mathrm{C} 12=\mathrm{C} 15$ & 1.341 & 1.342 & 1.341 & 1.335 & & & \\
\hline $\mathrm{C} 13=\mathrm{C} 18 ; \mathrm{C} 16=\mathrm{C} 19$ & 1.331 & 1.336 & 1.33 & & & & \\
\hline $\mathrm{C} 17=\mathrm{C} 21 ; \mathrm{C} 20=\mathrm{C} 22$ & 1.337 & 1.335 & & & & & \\
\hline \multicolumn{8}{|l|}{ Single bonds } \\
\hline $\mathrm{C} 1-\mathrm{C} 2 ; \mathrm{C} 3-\mathrm{C} 4$ & 1.46 & 1.46 & 1.46 & 1.461 & 1.462 & 1.468 & 1.507 \\
\hline $\mathrm{C} 5-\mathrm{C} 6 ; \mathrm{C} 7-\mathrm{C} 8$ & 1.471 & 1.471 & 1.471 & 1.472 & 1.477 & 1.51 & \\
\hline $\mathrm{C} 9-\mathrm{C} 10 ; \mathrm{C} 11-\mathrm{C} 12$ & 1.463 & 1.462 & 1.463 & 1.468 & 1.505 & & \\
\hline $\mathrm{C} 13-\mathrm{C} 14 ; \mathrm{C} 15-\mathrm{C} 16$ & 1.477 & 1.472 & 1.477 & 1.51 & & & \\
\hline $\mathrm{C} 17-\mathrm{C} 18 ; \mathrm{C} 19-\mathrm{C} 20$ & 1.494 & 1.468 & 1.505 & & & & \\
\hline
\end{tabular}

separated states were calculated for the cation of the 1,3-trans-butadiene molecule using UHF approach. The geometry of the singly charged 1,3trans-butadiene molecule was optimized from an initial input of the optimized structure of the neutral molecule. The D and the A state wavefunction were then generated by elongating the terminal $C$ atom of the molecule, one at a time, until the charge was localized at the other end. The $V_{\mathrm{DA}}$ was then calculated according to the approach of Farazdel and Dupuis [30]. For the KT approach, the HOMO and the NHOMO energies were taken from the UHF calculation on the charge neutral triplet state at its theoretically optimized geometry. All calculations were performed with the use of the HONDO-8 molecular electronic structure package

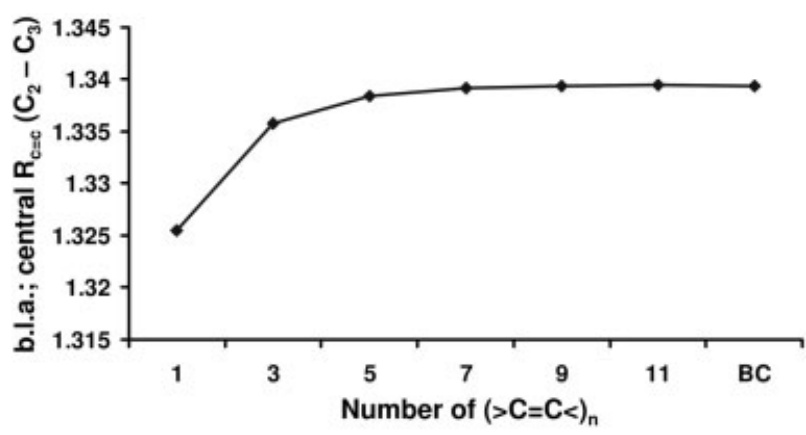

FIGURE 3. Bond length alternation (b.l.a.) as a function of the chain length of the polyene oligomers $(n=$ $1-11, \mathrm{BC}=\beta$-carotene).
[31] with the use of a double-zeta and polarization (DZP) basis set. The calculated geometry of the neutral molecule and its cation along with the values of $V_{\mathrm{DA}}$ obtained from the two approaches are listed in Table II. For comparison, available theoretical [32-34] and experimental [35] values of the geometry of 1,3-trans-butadiene are also listed in the table. As can be seen, the calculated bond distance and bond angles are in good agreement with the available experimental and calculated data. It is

\section{TABLE II}

The calculated geometry of the neutral and cation of the 1,3 trans-butadiene along with the values of $V_{\mathrm{DA}}$ obtained from MH two-state model and KT approach.

\begin{tabular}{lcc}
\hline Bond length $(\AA)$ & $\mathrm{C}=\mathrm{C}$ & $\mathrm{C}-\mathrm{C}$ \\
Neutral & $1.313^{\mathrm{a}}$ & $1.488^{\mathrm{a}}$ \\
& $1.322^{\mathrm{b}}$ & $1.467^{\mathrm{b}}$ \\
& $1.333^{\mathrm{c}}$ & $1.450^{\mathrm{c}}$ \\
& $1.339^{\mathrm{d}}$ & $1.454^{\mathrm{d}}$ \\
& $1.337 \pm 0.005^{\mathrm{e}}$ & $1.483 \pm 0.010^{\mathrm{e}}$ \\
Cation & $1.4617^{\mathrm{a}}$ & $1.5296^{\mathrm{a}}$ \\
$V_{\mathrm{DA}}(\mathrm{eV})$ & $0.18^{\mathrm{a}, \mathrm{f}} 0.17^{\mathrm{a}, \mathrm{g}}$ &
\end{tabular}

a Current work, HF(DZP).

b HF (Ref. [32]).

${ }^{c}$ DFT (Ref. [33]).

${ }^{d}$ MP2/6-311 (2d,p) (Ref. [34]).

e Experimental (Ref. [35]).

${ }^{f}$ MH Two-State Model.

g KT approach. 
also clear from the table that the $V_{\mathrm{DA}}$ obtained from $\mathrm{KT}$ approach is in very good agreement with that obtained from the $\mathrm{MH}$ two-state approach. Similar agreement between the values of $V_{\mathrm{DA}}$ obtained from the KT approach and from $\mathrm{MH}$ two-state models were found in our previous study on $\sigma$-bonded high-strain molecules $[9,26]$, where the magnitude of $V_{\mathrm{DA}}$ obtained from the KT approach were slightly underestimated with respect to its $\mathrm{MH}$ counterparts. This lends confidence in our use of the KT approach in the present study to investigate the length-dependence of $V_{\mathrm{DA}}$ of polyene oligomers.

\section{The $\mathbf{V}_{\mathrm{DA}}$ for Polyene Oligomers.}

The calculated values of $V_{\mathrm{DA}}$ for the $[>\mathrm{C}=\mathrm{C}<]_{n}$ oligomers with $n=1,3,5,7,9,11$ and $\beta$-carotene along with the molecular-chain length, calculated from end-C to end-C atoms in the chain, are listed in Table III. Also listed in the table is the difference in the energy, $\Delta \varepsilon$, between the HOMO and the lowest occupied molecular orbital (LUMO) value calculated for each molecule. It is clear that the value of $V_{\mathrm{DA}}$ decreases, as does $\Delta \varepsilon(\mathrm{HOMO}-$ LUMO), with increase in molecular length (see Fig. 4). In fact, the change in the value of $V_{\mathrm{DA}}$ with increasing molecular length exhibits very similar behavior as $\Delta \varepsilon(\mathrm{HOMO}-\mathrm{LUMO})$. This is consistent with and similar to the previous observations on the ET coupling matrix element in organic molecular systems $[2,18-20]$. The $\ln \left(V_{\mathrm{DA}}\right)$ vs. molecular length $\left(R_{\mathrm{DA}}\right)$ plot, shown in Figure 5, also clearly

\section{TABLE III}

Calculated values of $\Delta \varepsilon$ (HOMO-LUMO) in $\mathrm{eV}$ and electron transfer coupling strength, $V_{\mathrm{DA}}$ in $\mathrm{eV}$, for $[\mathrm{C}=\mathrm{C}]_{n}$ oligomers and $\beta$-carotene and its derivatives.

\begin{tabular}{lccc}
\hline $\begin{array}{l}\text { Molecule with the } \\
\text { number of } \pi- \\
\text { conjugated } \\
\text { bonds, } n\end{array}$ & $\begin{array}{c}\text { Length } \\
(\AA)\end{array}$ & $\begin{array}{c}\Delta \varepsilon \\
(\mathrm{HOMO}-\mathrm{LUMO}) \\
(\mathrm{eV})\end{array}$ & $\begin{array}{l}V_{\mathrm{DA}} \\
(\mathrm{eV})\end{array}$ \\
\hline 1 & 3.93 & 14.2 & 3.43 \\
3 & 8.78 & 10.3 & 1.91 \\
5 & 13.66 & 9.0 & 1.54 \\
7 & 18.44 & 8.3 & 1.24 \\
9 & 23.2 & 7.9 & 1.17 \\
11 & 27.30 & 7.7 & 1.07 \\
$\beta$-Carotene & 27.65 & 7.9 & 1.12 \\
\hline
\end{tabular}

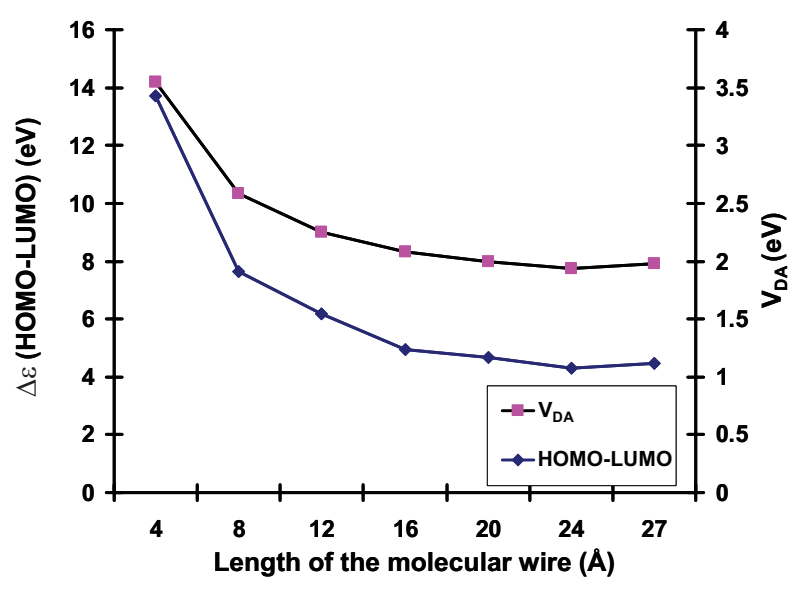

FIGURE 4. Calculated $\Delta \varepsilon(\mathrm{HOMO}-\mathrm{LUMO})$ and electron transfer coupling strength, $V_{D A}$, as a function of the length of the molecular wire.

demonstrates, as shown in other cases, an exponential decrease in the value of $V_{\mathrm{DA}}$.

The similarity with the observations made in other molecular systems, however, ends here. A closer examination of the $\ln \left(V_{\mathrm{DA}}\right)$ vs. $R_{\mathrm{DA}}$ plot (see Fig. 5), reveals that between the calculated range (3.93 and $27.65 \AA$ ) of molecular length, the $V_{\mathrm{DA}}$ has three different decay regimes. Indeed, the calculated value of the decay constant $\beta, 0.24,0.09$, and $0.03 \AA^{-1}$ between 3 and $9 \AA$, between 9 and $18 \AA$, and between 18 and $28 \AA$, respectively, appears to decrease roughly by a factor of 3 for every $9 \AA$ increase in the molecular length. At larger length, between the donor and acceptor centers, the $\pi$-con-

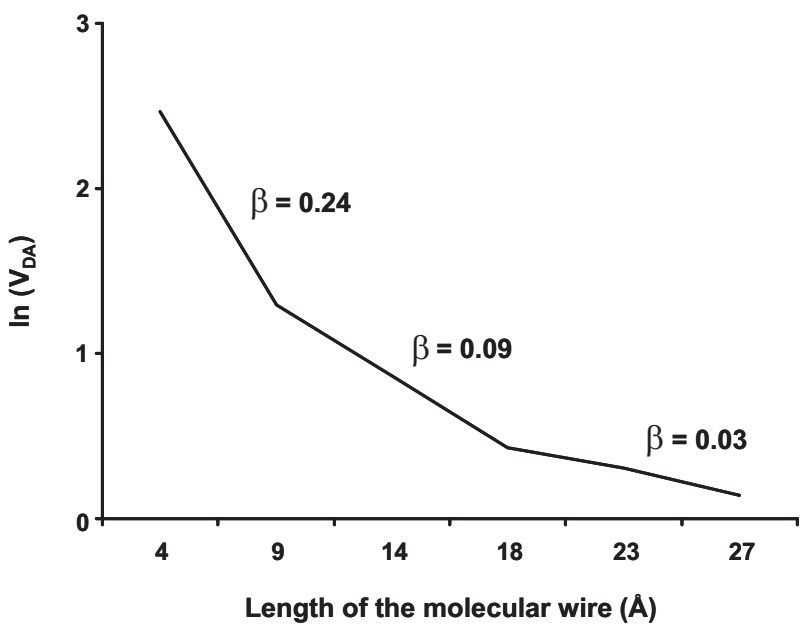

FIGURE 5. The variation of the electronic transfer coupling [see, Eq. (1)] with the molecular length. 


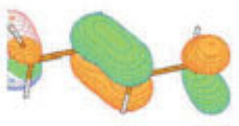

(i)

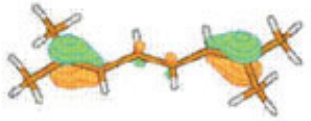

(i)

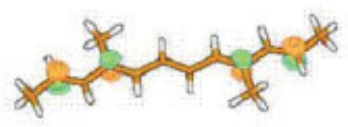

(i)

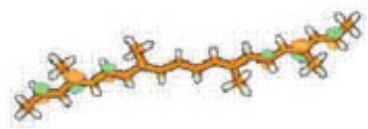

(i)

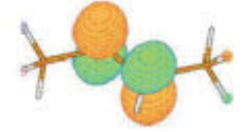

(ii)

(a)

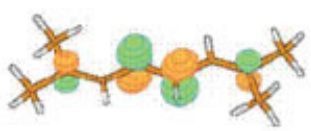

(ii)

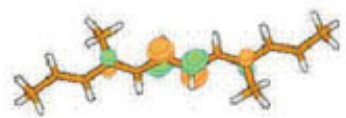

(ii)

(c)

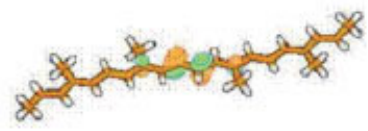

(ii)

(b)

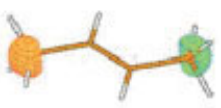

(iii)

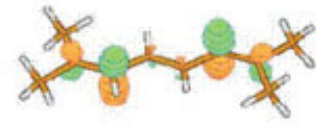

(iii)

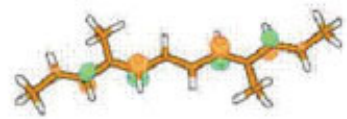

(iii)

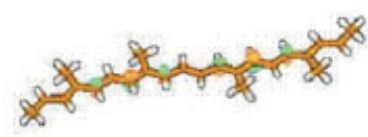

(iii)

(d)

FIGURE 6. Electron density contour map of the (i) HOMO-1, (ii) $\mathrm{HOMO}$, and (iii) LUMO of polyene $(>\mathrm{C}=\mathrm{C}<)_{n}$; $n=$ 1 (a), $n=3$ (b), $n=5$ (c), and $n=9$ (d).

jugated molecular wire appears to retain the coupling strength, however.

It is possible to gain insight into the noted nonmonotonic behavior of $\beta$ in the polyene oligomer from an examination of the spatial and energetic characteristics of the frontier orbitals (HOMO and LUMO) and HOMO-1 involved in the calculation of $V_{\mathrm{DA}}$ [Eq. (3)]. For brevity, the electron density contour map of the three molecular orbitals, HOMO-1,
$\mathrm{HOMO}$, and the LUMO, for selected polyene oligomers $(n=1,3,5$, and 9) are plotted in Figures 6(a)-(d). The corresponding MO plots of the missing members $(n=7,11$, and $\beta$-carotene) are similar to their nearest smaller member and are excluded for brevity. We note that the HOMO is an antibonding $\left(\pi_{\mathrm{g}}{ }^{*}\right)$ orbital, localized in the bonding region of the chain. In fact, the HOMO is essentially localized on the inner three double bonds (single in case of 
$n=1)$ regardless of the size of the molecule. The HOMO-1, on the other hand is delocalized for $n=$ 1 and $n=3$, and localized on the outer part of the chain for $n=5-11$. Specifically, the HOMO- 1 for $n=5-11$, is delocalized over the outer three $R_{\mathrm{C}}=\mathrm{C}$ in the chain. We also note that the $\Delta \varepsilon(\mathrm{HOMO}-$ (HOMO-1)) decreases with increasing chain length but no uniformity in the change is noted. The electronic structure characteristics of LUMO as well as $\Delta \varepsilon($ LUMO-HOMO) show very similar behavior as that noted for the HOMO-1. Similarly the changes in $\Delta \varepsilon$ (LUMO-HOMO) show similar nonuniformity as the $\Delta \varepsilon(\mathrm{HOMO}-(\mathrm{HOMO}-1))$ along the chain. These results suggest that electronic structure of polyene oligomers, especially for shorter members, could differ substantially from each other along the chain, resulting in different ET behavior.

Because electronic structure difference is expected to affect the geometry, which in turn is intimately connected with the ET property of the molecules, it is also instructive to examine the geometrical evolution of the oligomers with the chain length. As noted earlier, while the oligomers exhibit the expected b. 1. a. with increasing chain length, a somewhat nonuniform change in the bond lengths, particularly the $R_{\mathrm{C}=\mathrm{C}}$, is noted for smaller members. For example, a large increase in $R_{\mathrm{C}}=\mathrm{C}$ in going from $n=1$ to $n=3$ is noted, but only smaller changes in the value of $R_{\mathrm{C}=\mathrm{C}}$ between larger members are noted (see Fig. 3). Similar nonuniform changes in the bond lengths are also noted for $R_{\mathrm{C}-\mathrm{C}}$. This nonuniform evolution of the bond distance at shorter molecular lengths contributes to the nonmonotonic decay rate constant as noted. Thus, it appears that the different decay region, as calculated here for the family of polyenes, results from a combination of (a) change (dissimilarity) in electronic structure along the chain and (b) nonuniform change in $b$. 1. a. with increasing length.

Nonmonotonic decay of ET has been noted in other $\pi$ - and $\sigma$-bonded systems. For example, nonmonotonic variation of the decay rate with molecular length has been reported for $\pi$-conjugated aromatic molecular wires [36]. Nonmonotonic variation of the ET coefficient, $V_{\mathrm{DA}}$, has also been predicted for $\sigma$-bonded rigid-rod molecules from similar calculations [4-6], although subsequent calculations differ [20]. Ab initio Hartree-Fock calculations by Liang and Newton $[4,5]$ using the KT approach also show a nonmonotonic variation of $V_{\mathrm{DA}}$ with the increase in the number of bicyclo [2.2.2] octane cage units in a molecular rod. Although a change in electronic structure along the length appears to be a common factor, other mechanisms such as coherent vs. incoherent ET have also been proposed, especially for $\pi$-conjugated systems [37] to account for a nonmonotonic decrease in $\beta$ with increasing $R$.

\section{Summary}

In summary, we have calculated the geometry and ET properties of $\beta$-carotene and its smaller oligomers using ab initio Hartree-Fock method. The polyene oligomers exhibit the expected b. l. a. at larger molecular lengths. At shorter molecular lengths, however, large differences in chain lengths (both $R_{\mathrm{C}=\mathrm{C}}$ and $R_{\mathrm{C}-\mathrm{C}}$ ) are noted. To assess the accuracy of the results for the ET coupling matrix element obtained with the use of one-electron delocalized orbital energies, we calculated the value of $V_{\mathrm{DA}}$ for 1,3-trans-butadiene molecule at the optimized geometry using $\mathrm{MH}$ two-state model as well as with the KT approach. The result for $V_{\mathrm{DA}}$ calculated from the KT approach shows good agreement with that obtained from the more rigorous $\mathrm{MH}$ two-state approach giving confidence in the results for $V_{\mathrm{DA}}$ obtained for the polyene oligomers using the former approach. The ET coupling matrix element for the polyene oligomers shows different decay regimes, with the value of decay constant decreasing with increasing length of the molecular wire, which appear to result from a combination of changes in electronic charge distribution of the HOMO-1 (and LUMO) orbitals as well as the differences in b. l. a. along the chain. A clear correlation between change in $V_{\mathrm{DA}}$ and b.l.a. is noted along the molecular chain. It appears that with increasing molecular length the b.l.a. becomes nearly constant with little or no change beyond $n>$ 5 . The change in $V_{\mathrm{DA}}$ qualitatively show a parallel behavior and remains nearly unchanged for polyenes with $n>5$. Thus, it seems that $V_{\mathrm{DA}}$ is strongly related to the geometry, particularly the b.l.a. in conjugated polyenes. As expected, the geometrical effect is also reflected in the change in $\Delta \varepsilon(\mathrm{HOMO}$ LUMO), which decreases sharply with increasing molecular length for small values of $n$, but stabilizes around $n=5$ and exhibit little or no change beyond $n=7$. These results clearly show the $V_{\mathrm{DA}}$ is strongly related to b.l.a. and $\Delta \varepsilon$ (HOMO-LUMO) in conjugated polyenes. It would be of interest to examine the decay of $\beta$ in an idealized polyene with constant b.l.a. This will be addressed in forth coming article [38]. At very large chain length, such as 
in $n=9-11$ and $\beta$-carotene, the decay rate appears to have a very small value, suggesting their potential applications as interconnect in molecular and nanoscale electronics and sensor devices.

\section{References}

1. Larsson, S.; Volosov, A. J Chem Phys 1987, 87, 6623.

2. Aviram, A. J Am Chem Soc 1988, 110, 5687.

3. Naleway, C. A.; Curtiss, L. A.; Miller, J. R. J Phys Chem 1991, 95, 8434 .

4. Liang, C.; Newton, M. D. J Phys Chem 1992, 96, 2855.

5. Liang, C.; Newton, M. D. J Phys Chem 1993, 97, 3199.

6. Paulson, B. P.; Curtiss, L. A.; Bal, B.; Closs, G. L.; Miller, J. R. J Am Chem Soc 1996, 118, 378.

7. Newton, M. D. Adv Chem Phys 1999, 106, 303.

8. Hall, L. E.; Reimers, J. R.; Hush, N. S.; Silverbrook, K. J Chem Phys 2000, 112, 1510.

9. Pati, R.; Karna, S. P. J Chem Phys 2001, 115, 1703.

10. Sikes, H. D.; Smalley, J. F.; Dudek, S. P.; Cook, A. R.; Newton, M. D.; Chidsey, C. E. D.; Feldberg, S. W. Science 2001, 291, 1519.

11. Leland, B. A.; Joran, A. D.; Felker, P. M.; Hopfield, J. J.; Zewail, A. J.; Dervan, P. B. J Phys Chem 1985, 89, 5571.

12. Piva, P. G.; DiLabio, G. A.; Pitters, J. L.; Zikovsky, J.; Rezeq, M.; Dogel, S.; Hofer, W. A.; Wolkow, R. A. Nature 2005, 435, 658.

13. Durig, U.; Zuger, O.; Michel, B.; Haussling, L.; Ringsdorf, H. Phys Rev B 1993, 48, 1711.

14. Boulas, C.; Davidovits, J. V.; Rondelez, F.; Vuillaume, D. Phys Rev Lett 1996, 76, 4797.

15. Bumm, L. A.; Arnold, J. J.; Cygan, M. T.; Dunbar, T. D.; Burgin, T. P.; Jones, L., II; Alara, D. L.; Tour, J. M.; Weiss, P. S. Science 1996, 271, 1705.

16. Reed, M. A.; Zhou, C.; Muller, C. J.; Burgin, T. P.; Tour, J. M. Science 1997, 278, 252.

17. Tian, W.; Dutta, S.; Hong, S.; Reifenberger, R.; Henderson, J. I.; Kubiak, C. P. J Chem Phys 1998, 109, 2874.

18. Ramachandran, G. K.; Tomfohr, J. F.; Li, J.; Sankey, O. F.; Zarate, X.; Primak, A.; Terazono, Y.; Moore, T. A.; Moore, A. L.; Gust, D.; Nagahara, L. A.; Lindsay, S. M. J Phys Chem B 2003, 107, 6162 .

19. He, J.; Chen, F.; Li, J.; Sankey, O. F.; Terazono, Y.; Herrero, C.; Gust, D.; Moore, T. A.; Moore, A. L.; Lindsay, S. M. J Am Chem Soc 2005, 127, 1384.
20. Pati, R.; Karna, S. P. Chem Phys Lett 2002, 351, 302.

21. Marcus, R. A.; Sutin, N. Biochim Biophys Acta 1985, 811, 265.

22. Hush, N. S. Electrochim Acta 1968, 13, 1005.

23. Newton, M. D. Chem Rev 1991, 91, 767.

24. Curtiss, L. A.; Naleway, C. A.; Miller, J. R. J Phys Chem 1993, 97, 4050 .

25. Koopmans, T. Physica 1934, 1, 104.

26. Pati, R.; Pineda, A. C.; Karna, S. P.; Pandey, R. Chem Phys Lett 2005, 406, 483.

27. Frisch, M. J.; Trucks, G. W.; Schlegal, H. B.; Scuseria, G. E.; Robb, M. A.; Cheeseman, J. R.; Zakrzewski, V. G.; Montgomery, J. A. Jr.; Stratmann, R. E.; Burant, J. C.; Dapprich, S.; Millam, J. M.; Daniels, A. D.; Kudin, K. N.; Strain, M. C.; Farkas, O.; Tomasi, J.; Barone, V.; Cossi, M.; Cammi, R.; Mennucci, B.; Pomelli, C.; Adamo, C.; Clifford, S.; Ochterski, J.; Petersson, G. A.; Ayala, P. Y.; Cui, Q.; Morokuma, K.; Salvador, P.; Dannenberg, J. J.; Malick, D. K.; Rabuck, A. D.; Raghavachari, K.; Foresman, J. B.; Cioslowski, J.; Ortiz, J. V.; Baboul, A. G.; Stefanov, B. B.; Liu, G.; Liashenko, A.; Piskorz, P.; Komaromo, I.; Gomperts, R.; Martin, R. L.; Fox, D. J.; Keith, T.; Al-Laham, M. A.; Peng, C. Y.; Nanyakkara, A.; Challacombe, M.; Gill, P. M. W.; Johnson, B.; Chen, W.; Wong, M. W.; Andres, J. L.; Gonzalez, C.; Head-Gordon, M.; Replogle, E. S.; Pople, J. A. Gaussian 98, Revision A.11; Gaussian Inc: Pittsburgh, PA, 2001.

28. Himo, F. J Phys Chem A 2001, 105, 7933.

29. Sterling, C. Acta Crystallogr 1964, 17, 1224.

30. Farazdel, A.; Dupuis, M. J Comput Chem 1991, 12, 27.

31. Dupuis, M.; Farazdel, A.; Karna, S. P.; Maluendes, S. A. In Modern Technique in Computational Chemistry; Clementi, E., Ed.; ESCOM: Leiden, 1990; p 324.

32. Bock, W. C.; George, P.; Trachtman, M. Theor Chim Acta 1984, 64, 293.

33. Craig, N. C.; Oertel, M. C.; Oertel, D. C.; Tubergen, M. J.; Laverich, R. J.; Chaka, A. M. J Phys Chem A 2002, 106, 4230.

34. Lee, J. Y.; Haln, O.; Lee, S. J.; Choi, H. S.; Shim, H.; Mhin, B. J.; Kim, K. S. J Phys Chem 1995, 99, 1913.

35. Sutton, L. E., Eds. Tables of Interatomic Distances and Configuration in Molecules and Ions; Special Publication No. 11; The Chemical Society: Burlington House, London, 1958.

36. Craig, N. C.; Groner, P.; McKean, D. C. J Phys Chem A 2006, $110,7461$.

37. Davis, W. B.; Svec, W. A.; Ratner, M. A.; Wasielewski, M. R. Nature 1998, 396, 60.

38. Mallick, G.; Karna, S. P.; He, H.; Pandey, R. Chem Phys Lett 2009 (in press). 